\title{
IMPLANTAÇÃO DE PROGRAMAS DE GERENCIAMENTO DE RESídUOS QUÍMICOS LABORATORIAIS EM UNIVERSIDADES: ANÁLISE CRÍTICA E RECOMENDAÇÕES
}

\section{ESTABLISHMENT OF LABORATORY WASTE MANAGEMENT PROGRAMS IN UNIVERSITIES: CRITICAL REVIEW AND RECOMMENDATIONS}

\author{
FELIPE RUFINE NOLASCO \\ Graduando em Engenharia Ambiental, EEP \\ GLAUCO ARNold TAVARES
}

Químico Industrial. Doutor em Ciências. Gestor do Programa de Gerenciamento de Resíduos do CENA/USP

\author{
José Albertino BendASSOLLI
}

Engenheiro Químico. Doutor em Ciências. Pesquisador do LIE - CENA/USP

Recebido: 13/04/05 Aceito: 04/05/06

\section{RESUMO}

Programas de Gerenciamento de Resíduos Químicos Laboratoriais vêm sendo implantados em várias universidades do país e do mundo, em reconhecimento à necessidade premente de alterar a realidade de descaso para com o ambiente, associado à responsabilidade objetiva do gerador e, principalmente, à consciência de sustentabilidade, em consonância com a Agenda 21. Neste contexto, o presente trabalho relata essa problemática de forma a reunir uma série de informaçôes por meio de revisão da literatura recente, desenvolvendo uma análise crítica e desmistificando alguns (pré) conceitos através de um questionário aplicado aos pesquisadores atuantes nesta área de conhecimento. Esse estudo permitiu, por fim, a proposição de regras básicas a serem adotadas na implementação de um programa de gerenciamento de resíduos laboratoriais.

PALAVRAS-CHAVE: Gerenciamento de resíduos, resíduos laboratoriais, segurança em química, educação ambiental.

\begin{abstract}
Laboratory Waste Management Programs have been established in several universities all over the world. These programs are important because they provide the understanding and protection of the environment, encouraging the waste generator's responsibility and, mainly, accomplishing sustainable practice in the laboratory, in accordance with the Agenda 21. In this context, based on a literature review, the present work discusses the subject, introducing some recommendations to be applied in universities. A questionnaire applied to researchers of this area shows important information about the start of the programs, mainly difficulties, among other cares. This study allowed the proposition of basic rules about the establishment of laboratory waste management.
\end{abstract}

KEYWORDS: Waste management, laboratorial wastes, chemistry security, environmental education.

\section{INTRODUÇÃO}

Problemas de ordem ambiental geram efeitos globais das mais variadas espécies e ordens de grandeza, razão pela qual cada situação deve ser tratada respeitando-se suas particularidades. A partir da AGENDA 21, foi adotado como lema, à cada individuo, entidade ou instituição, "Pensar Globalmente e Agir Localmente".

Assim sendo, a geração pontual de resíduos químicos configurou-se em um dos problemas a serem contornados, sobretudo nas indústrias. Todavia, sabe- se que os profissionais que atuam nesse segmento não receberam formação adequada para lidar com esses problemas nos bancos escolares, também porque as próprias instituições de ensino e pesquisa não tratavam seus resíduos químicos de atividades laboratoriais até pouco tempo atrás. Felizmente, na atualidade, algumas das melhores e mais conceituadas instituições do país demonstram-se preocupadas com a questão, tendo iniciado o gerenciamento dos seus resíduos, colocando em prática a denominada "Responsabilidade Objetiva” (Lei 6.938/81 da Política Nacional do Meio Ambiente), isto é, o gerador torna-se responsável pelo resíduo e pelos possíveis danos causados quando esses forem descartados no ambiente.

Assim como em vários segmentos, nos quais a Gestão Ambiental vem sendo praticada, nas universidades foram criados modelos de gerenciamento de resíduos, respeitando desde os tipos e volumes desses materiais, até as restrições impostas pelos órgãos de fiscalização ambiental estaduais. Desse modo, o presente trabalho pretende, partindo de uma revisão de literatura sobre os modelos de gerenciamento de resíduos 
químicos laboratoriais adotados em Instituições de Ensino e Pesquisa no Brasil na última década, e de um questionário aplicado aos responsáveis pela implementação desses programas, caracterizar os principais avanços e dificuldades encontradas, de modo a elaborar uma Estrutura Modelo passível de aplicação direta na grande maioria das instituições que intentem enveredar pelo mesmo caminho. Outro aspecto importante que virá a reboque desse instrumento é que, além dele ser uma ferramenta de Gestão Ambiental, serve também para Educação Ambiental. Esta, por sua vez, tende a resgatar a consciência perdida do sustentável, proporcionando a união do indivíduo que hoje se encontra em um modelo de sociedade que prioriza o desenvolvimento a qualquer custo, com o meio em que vive, partindo do princípio de que somente existe o sustentável, quando precedido por princípios incondicionais de altruísmo e respeito à vida.

\section{PRÁTICAS CORRENTES NO BRASIL}

\section{Panorama referente à implementação de programas de gerenciamento de resíduos no ambiente universitário}

A questão dos Resíduos Laboratoriais é um tema mundialmente discutido, principalmente nas universidades e centros de pesquisas de países desenvolvidos. Os principais centros de pesquisas na área de química vêm estudando alternativas para garantir a continuidade dos trabalhos, sem que para isso haja a necessidade de degradar o ambiente, ou seja, existe já há algum tempo a preocupação com o desenvolvimento sustentável. Ashbrooh \& Reinhardt (1985) citam várias instituiçōes que implantaram seus PGR a partir da década de 70, como a Universidade da Califórnia, a Universidade de Winscosin, a Universidade do Estado do Novo México, a Universidade de Illinois e a Universidade de Minnesota. Nessas duas últimas, foram enumerados aproximadamente 2000 produtos químicos utilizados em rotina, resultando em ampla variedade de materiais residuais. Izzo (2000) também relata interessante programa de prevenção à poluição e minimização da geração de resíduos nos laboratórios da Universidade de Prin- ceton. Algumas experiências também resultaram na publicação de livros sobre a questão, apresentando inclusive métodos de tratamento para alguns tipos de resíduos (Kaufman, 1990; Lunn \& Sanzone, 1994; Amour, 1996).

No Brasil, experiências nesse sentido vêm sendo realizadas na última década, principalmente em algumas das maiores e mais antigas universidades estaduais e federais. Merecem destaque e serão abordados no decorrer deste texto os trabalhos desenvolvidos nos seguintes institutos/universidades: IQ/USP - Instituto de Química da Universidade de São Paulo (Di Vitta et al, 2002); IQSC/USP - Instituto de Química da Universidade de São Paulo do Campus São Carlos (Alberguini et al, 2003); CENA/USP - Centro de Energia Nuclear na Agricultura da Universidade de São Paulo (Tavares, 2004); UNICAMP - Universidade de Campinas (Coelho et al, 2002); IQ/UERJ - Instituto de Química da Universidade do Estado do Rio de Janeiro (Barbosa et al, 2003); DQ/UFPR - Departamento de Química da Universidade Federal do Paraná (Cunha, 2001); IQ/UFRGS - Instituto de Química da Universidade Federal do Rio Grande do Sul (Amaral et al, 2001); UCB - Universidade Católica de Brasília (Dalston et al, 2004); UFSCar - Universidade Federal de São Carlos (Sassiotto et al, 2004); FURB - Universidade Regional de Blumenau (Zanella, 2004); URI - Universidade Regional Integrada do Alto Uruguai e das Missōes (Demaman et al, 2004); UFRJ - Universidade Federal do Rio de Janeiro (Afonso et al, 2004); UNIVATES - Centro Universitário Univates (Bersch et al, 2004). Convém esclarecer, ainda, que o critério de seleção destes programas foi baseado em detalhada revisão da literatura recente, e não reflete a totalidade das instituiçốes preocupadas com a questão.

Como poderá ser observado ao longo do texto, ainda que a intenção dessas instituiçõos seja semelhante, há inúmeras particularidades, que se iniciam na geração do resíduo a ser gerenciado e persistem até a disposição final, justificando a adoção de procedimentos distintos.

\section{Praticas de gerenciamento}

Há basicamente dois tipos de resíduos gerados em laboratórios de ensino e pesquisa: o ativo, que é fruto das atividades rotineiras da unidade geradora e principal alvo de um programa de gerenciamento, e o passivo, que compreende o resíduo estocado, geralmente não caracterizado, aguardando a destinação final (Jardim, 1998). Ressalta-se, no entanto, que a maioria das universidades não dispõe do passivo, o que facilita o estabelecimento de um programa de gerenciamento, mas, por outro lado, mostra o descaso com que o assunto vem sendo tratado até os dias atuais. São poucas as instituiçôes que mencionam a existência do passivo, que gerenciam resíduos descaracterizados, e que possuem um depósito adequado para o seu armazenamento. Exemplos são o IQSC/USP e o CENA/USP (Alberguini et al, 2003; Tavares, 2004).

Com relação ao ativo, a grande diversidade observada na geração entre as universidades é devida às linhas de pesquisa desenvolvidas em cada instituição, o que resulta na geração de resíduos também diferentes, em espécie e volume. Enquanto em algumas instituiçōes, em termos de volume, solventes orgânicos são gerados em grandes quantidades (UNICAMP, IQSC/USP, IQ/USP e UFSCar), nas demais, soluçôes inorgânicas é que são geradas em maiores quantidades.

A principal regra a ser adotada para o gerenciamento dos resíduos é a da responsabilidade objetiva, isto é, quem gera o resíduo torna-se responsável pelo mesmo. A Lei 6938, de 31 de agosto de 1981, mais conhecida como Política Nacional do Meio Ambiente, estabelece que a responsabilidade objetiva dispensa a prova de culpa no caso de um possível dano ao ambiente, ou seja, para que um potencial poluidor seja penalizado, basta que se prove um nexo de causa e efeito entre a atividade desenvolvida por uma organização e um dano ambiental. Em resumo, significa que um resíduo poluidor, ainda que esteja sendo emitido em concentrações que respeitem os limites estabelecidos pela legislação vigente, poderá causar um dano ambiental, e sujeitar o causador do dano ao pagamento de uma indenização, ou também, um dano indireto, desde que seja provada sua relação com uma dada instituição, a mesma será responsabilizada (Machado, 2002).

A segregação dos resíduos em diferentes classes de compatibilidade é outra prática importante na hierarquia 
do gerenciamento, e a decisão dos procedimentos a serem seguidos está atrelada ao destino final dos resíduos (Reel, 1993). No caso do CENA/USP (Tavares, 2004) foram estabelecidas 11 classes - A) Mercúrio e resíduos de seus sais inorgânicos; B) Solventes orgânicos e soluçōes de substâncias orgânicas que não contenham halogênios ; $\mathrm{C}$ ) Resíduos de sais metálicos regeneráveis; D) Solventes orgânicos e soluçôes orgânicas que contenham halogênios; E) Resíduos inorgânicos tóxicos contendo metais pesados; F) Resíduos sólidos de produtos químicos orgânicos; $\mathrm{G}$ ) Soluções salinas (pH 6 - 8); H) Soluções que contenham cianetos/nitrilas ou geradoras de CN; I) Compostos explosivos ou combustíveis tóxicos; J) Resíduos inorgânicos tóxicos não contendo metais pesados ; K) Outros compostos (tintas, resinas diversas, óleo de bomba de vácuo; herbicidas, pesticidas). Por outro lado, na UNICAMP, UNIVATES e UFPR os resíduos gerados puderam ser separados em apenas 6 classes e, ainda assim, divergindo entre si (Cunha, 2001; Coelho et al, 2002; Bersch, 2004).

\section{Hierarquia da gestão}

A implantação de um PGR deve obedecer a uma escala de prioridades que estimule, a princípio, a prevenção da geração de residuos, isto é, deve-se evitar sempre que possível a geração. Isso pode ser obtido pela modificação de um processo qualquer (ou método analítico), substituição de matériasprimas ou insumos. Embora seja esta a primeira e principal prática a ser implementada, é também a mais difícil de ser atingida, uma vez que a busca incessante por resultados é uma realidade atual, e o desenvolvimento, nesse caso, é pontual. Em pesquisas que vêm sendo desenvolvidas desde seu início empregando determinado procedimento é inadequada uma mudança metodológica em algumas situações, sob o risco de trazer prejuízo aos resultados obtidos. Entretanto, embora não devidamente relatados, nos trabalhos de divulgação dos PGR analisados, pesquisas desenvolvidas nessas mesmas instituiçôes acabam, indiretamente, evitando a geração de resíduos.

Para se determinar mercúrio em solos ou sedimentos, por exemplo, foi substituída a metodologia clássica da geração de vapor frio (Bartllet \&
McNabb, 1947), que gera considerável volume de solução residual ácida contendo elevada concentração em estanho, por outra baseada na pirólise direta da amostra sólida (Magalhães et al,1997). Há ainda outros vários exemplos de métodos analíticos mais "limpos" que contribuem nesse sentido (Reis et al, 1997; Sartini et al, 1997, Lourenção et al, 2004).

Quando não é possível prevenir a geração de resíduos, muitas vezes é possível minimizá-la. Exemplo disso é a substituição do uso de buretas de 20 e $50 \mathrm{~mL}$ de capacidade nas práticas de laboratório (principalmente em atividades de ensino) por técnicas em microescala, que proporcionam resultados com semelhantes exatidão $\mathrm{e}$ precisão, apresentando ainda vantagens de consumir menos reagente e gerar menos resíduos (Singh et al, 2000). Outros exemplos são os métodos de análise por injeção em fluxo (Zagatto et al, 1981) e a elaboração de cadeias de experimentos em aulas de graduação, de modo que os produtos de uma prática sirvam de reagente noutra, sucessivamente (Schneider \& Wiskamp, 1994). Dentre os PGR implementados, é devidamente reconhecida a importância desta etapa. Todavia, não há muitos relatos de sua aplicação prática, sendo uma das exceções o exemplar trabalho desenvolvido na UFRGS, onde as disciplinas de graduação estão sendo estruturadas de forma que sejam produzidos em atividades práticas produtos ou subprodutos que possam ser utilizados noutras, sucessivamente (Amaral et al, 2001).

$\mathrm{Na}$ seqüência, deve-se estimular o reaproveitamento do resíduo inevitavelmente gerado, podendo ser realizado através da reciclagem, recuperação ou reutilização. As definiçōes sobre essa terminologia são variadas, mas Tavares (2004) explica que reciclar é refazer o ciclo por completo, voltar à origem, ou seja, é quando determinado material retorna como matéria-prima ao seu processo produtivo. Recuperar é retirar do resíduo um componente energético de interesse, seja por questôes ambientais, financeiras ou ambas concomitantemente. Já a reutilização ou reuso é quando um resíduo é utilizado, tal qual foi gerado, em um processo qualquer, dentro ou fora da unidade geradora.

O trabalho desenvolvido no CENA/USP é talvez aquele onde o reaproveitamento é mais enfaticamente praticado. Nesta unidade, são reutiliza- das soluçôes aquosas residuais contendo amônia e hidróxido de sódio no enriquecimento de isótopos e tratamento de resíduos, são recuperados prata e bromo contidos em soluçôes residuais e reciclados cobre metálico e solventes (Bendassolli et al, 2002; Bendassolli et al, 2003; Tavares, 2004). Nas demais instituiçóes, os exemplos de reaproveitamento estão relacionados principalmente com a reciclagem de solventes orgânicos. Para se ter uma noção do volume gerado, apenas no IQ/USP o montante atinge mais de 15.000 litros anualmente, sendo grande parte reciclado (Di Vitta et al, 2002). Nas demais instituiçōes, onde solventes orgânicos são gerados em grandes quantidades, a reciclagem também vêm sendo praticada, embora, muitas vezes, seja inviabilizada pela não segregação dos resíduos no ato da geração (Afonso et al, 2004).

O tratamento é a penúltima prática a ser realizada, definida na escala de prioridades, podendo ser químico, físico, biológico ou térmico. Enquanto o tratamento biológico é mais recomendado para grandes volumes de resíduos, principalmente orgânicos, o que não é o caso dos resíduos de laboratórios, e o tratamento térmico (freqüentemente a incineração) é considerado dispendioso, os métodos físicos e químicos são os mais promissores. Todos os PGR citados praticam alguma forma de tratamento, e as mais usuais são a neutralização ácido/base e a precipitação química de metais. Nas unidades onde os trabalhos estão em fase inicial, como na UFPR, UCB, FURB, URI e UNIVATES, essas acabam sendo as principais atividades relatadas, o que se justifica pela praticidade metodológica e por eximir a necessidade de equipamentos sofisticados.

Por fim, deve-se dispor adequadamente os resíduos, o que pode ser realizado em aterros ou outros locais apropriados. É comum a confusão de que incineração e co-processamento são formas de disposição final. Entretanto, em ambos os processos, há a queima do material residual e as conseqüentes geraçōes de gases (que deverão sofrer tratamento) e a formação de cinzas, que serão posteriormente direcionadas a um aterro, no caso da incineração, ou podem ser incorporadas à massa do cimento ou durante a formação do clínquer no forno, além da agregação em outras atividades da construçāo civil, como tijolos ou pavimentação. 
É interessante notar, entretanto, que essa escala de prioridades (evitar $\rightarrow$ minimizar $\rightarrow$ reaproveitar $\rightarrow$ tratar $\rightarrow$ dispor) é, na maioria das vezes, observada no sentido inverso, o que geralmente inviabiliza a atividade gerenciadora. Em outras palavras, a primeira preocupação consiste, freqüentemente, em encontrar alternativa para a disposição do resíduo. É nesse instante que a dimensão do problema remonta à anterior necessidade de que, se o resíduo tivesse sido tratado, reaproveitado, e/ou minimizado, não haveria quantidade tão acentuada para dispor. Ou ainda, talvez, o mesmo nem precisasse ser gerado (evitar a geração), sendo substituída a matéria-prima por outra de menor toxicidade.

\section{Identificação dos resíduos gerados}

No ato da geração dos resíduos nos laboratórios, se não houver a correta identificação dos materiais, inviabilizam-se as demais etapas da gestão, principalmente porque obriga a realização de um moroso procedimento para a caracterização qualitativa do resíduo (Jardim, 1998). Logicamente, quanto aos resíduos passivos, não há outra alternativa. Porém, esforços estão sendo envidados para a padronização da identificação dos resíduos gerados em rotina, embora, novamente, cada instituição esteja propondo rótulos com diferentes discriminações para os mesmos tipos de resíduos.

Enquanto no CENA/USP o preenchimento dos rótulos requer poucas informaçôes, restringindo-se a identificar basicamente o constituinte principal e sua concentração aproximada (Tavares, 2004), outras universidades estabeleceram fichas de acompanhamento do resíduo contendo descrições detalhadas (Cunha, 2001; Demanan, 2004). Já no IQSC/USP, definiu-se a rotulagem através de uma modificação no diagrama de Hommel, que estabelece o grau de risco à saúde, inflamabilidade e reatividade do resíduo (Alberguini et al, 2003).

\section{Segurança no manuseio, tansporte e armazenamento}

A segurança é a principal preocupação com relação ao transporte, manuseio e armazenamento temporário, uma vez que os resíduos devem ser transportados para outros locais a fim de serem tratados ou destinados corretamente. Assim sendo, a disponibilização de equipamentos de proteção individual e coletiva é primordial. A questão da segurança em química é tão importante que há 6 anos vem sendo realizado no Brasil um congresso bianual, o ENSEQUI (Encontro Nacional de Segurança em Química), que é um fórum específico para a discussão dessa temática.

Para o armazenamento temporário dos resíduos, tanto no laboratório quanto em um depósito, atenção também deve ser dada à segurança. Os recipientes empregados para esse armazenamento e transporte vão desde garrafas PET (Mortari et al, 2003) até mesmo recipientes especiais, como é o caso do PGR do CENA/USP (Tavares, 2004). Coerentemente, caso a entidade não disponha de recursos financeiros para a aquisição de recipientes apropriados, alternativas como o uso de frascos de reagentes, bombonas, entre outros, devem ser estimuladas.

É importante frisar, por fim, que para a realização de procedimentos fora dos limites físicos da unidade geradora, há que se requerer licença para o transporte dos resíduos junto aos órgãos fiscalizadores do meio ambiente, como por exemplo, no caso do Estado de São Paulo, a CETESB, através da emissão do CADRI - Certificado de Aprovação da Destinação de Resíduos Industriais.

Outro fator importante é o transporte interno, sendo que este pode variar de acordo com a estrutura das instituições. Para instalações prediais verticais podem ser utilizados elevadores internos ou externos, já no caso de instalaçôes horizontais podem ser utilizados carrinhos de carregamento individual e de pequenos volumes, não motorizados, ou até mesmo, de acordo com a necessidade e disponibilidade financeira e logística de transporte de cada instituição, carrinhos automotores para carregamento de vários e maiores volumes.

\section{Instrumentos auxiliares (Internet, treinamento e divulgação)}

As experiências relatadas na literatura descrevem bem a necessidade do treinamento de pessoal, de modo a qualificá-los, fazendo destes agentes de disseminação do PGR. Essas atividades, em algumas situaçóes, acabam sendo realizadas por pessoal externo, de modo que o conhecimento adquirido possa trazer melhorias locais.

Uma vez instalado, um programa de gerenciamento de resíduos laboratoriais em uma instituição envolve, freqüentemente, um elevado número de pessoas. Desse modo, a formatação de vias de intercomunicação na unidade facilita a manutenção e continuidade do programa. A rede mundial de computadores (internet) vem sendo bastante utilizada para esse fim, facilitando a comunicação e o acesso às informaçôes pertinentes ao PGR. Programas de controle de estoque de reagentes e resíduos também estão sendo desenvolvidos, possibilitando uma maior rastreabilidade das substâncias utilizadas (Tavares, 2004).

A divulgação para público alvo externo, através de trabalhos publicados em anais de eventos científicos, periódicos, etc, também massifica a importância da temática. Deve-se fazer, no entanto, uma ressalva quanto a isso. Lamentavelmente, grande parte dessas publicações não se refere ao desenvolvimento de métodos de tratamento, o que deveria ser estimulado, afim de facilitar suas aplicações em outras unidades de ensino e pesquisa.

\section{Particularidades verificadas nos PGR}

A revisão dos documentos mostrou uma homogeneidade significativa com relação aos princípios adotados nas distintas universidades. De uma maneira geral, visualiza-se uma estrutura gerencial padrão, que acaba sendo moldada de acordo com as condiçôes técnico/operacionais e permissibilidade dos órgãos ambientais estaduais. Enquanto no Estado de São Paulo é permitida a incineração de uma variedade de compostos, a legislação do Estado do Rio Grande do Sul proíbe esse procedimento, o que faz com que a UFRGS, ao optar por essa técnica, tenha de enviar seu material para outro Estado (Amaral et al, 2001). Por outro lado, diferentemente do Estado de São Paulo, no Paraná, o co-processamento de ácidos, bases, solventes halogenados ou não, cianetos e sais de vários metais é permitido. Valendo-se dessa permissibilidade, a técnica tem possibilitado a implantação de um PGR factível e de baixo custo na UFPR (Cunha, 2001). 
Com relação aos resíduos tratados, estes são freqüentemente materiais líquidos ou sólidos. Um único PGR, desenvolvido no CENA/USP, contempla o controle da emissão de resíduos gasosos, que deveriam merecer semelhante atenção. Nesta instituição foram instalados lavadores de gases para vapores ácidos e orgânicos, acoplados ao sistema de exaustão de capelas (Tavares, 2004).

O controle no desperdício de água e energia também é deixado de lado na maioria dos programas. Considerando que o uso de água com diminuta concentração iônica (baixa condutividade) é necessário para a realização dos procedimentos de rotina laboratorial, o processo convencional de destilação é a técnica de purificação mais empregada, processo esse que desperdiça acentuado volume de água (refrigeração) e consome grande quantidade de energia $\left(0,7 \mathrm{kw} \mathrm{L}^{-1}\right.$ de água produzida). Embora algumas instituições promovam o reuso da água de refrigeração que seria desperdiçada, é novamente no PGR do CENA/USP que o problema é enfrentado mais acuradamente, através da proposta de substituição do uso de destiladores pela técnica de troca iôni$\mathrm{ca}$, que vem propiciando significativa economia para a instituição (Tavares et al, 2004).

$\mathrm{Na}$ proposta em desenvolvimento de gerenciamento ambiental da UNICAMP (Coelho et al, 2002), os resíduos químicos são apenas um apêndice de um amplo programa, que contempla, além dos demais resíduos laboratoriais (biológicos e radioativos), $\mathrm{o}$ gerenciamento de resíduos domésticos, a cobertura vegetal, a logística de circulação e até mesmo a zoonose e controle de vetores. Para dar conta de tudo isso, criou-se uma célula operacional, ligada à reitoria da instituição, que contempla 4 profissionais dedicados única e exclusivamente a operacionalizarem a implantação do programa. É preciso pontuar, entretanto, que a UNICAMP, pela sua dimensão e volume de pessoas que circulam diariamente, pode ser considerada uma cidade, e que, logicamente, instituiçôes menores podem e devem ser menos ambiciosas.

\section{ENTREVISTAS}

Uma preocupação que derivou do estudo da questão foi procurar elucidar em que condiçōes os PGR estudados vinham sendo implementados, infor- mações essas indisponíveis na literatura. Com isso, optou-se por submeter um questionário composto por três questões, aos idealizadores dos PGR que foram citados ao longo do texto. Estas foram enviadas através de correio eletrônico sendo que quase a totalidade (15 em um total de 18) das pessoas consultadas respondeu prontamente ao questionamento.

De posse das respostas, entendeu-se por bem que não se justificaria a transcrição, na íntegra, do conteúdo. Assim sendo, optou-se por interpretar as argumentações dos entrevistados, traçando um cenário que melhor reflita as opiniōes gerais. Ainda, algumas das ponderações foram transcritas, e refletem literalmente a opinião desses professores.

A seguir estão as indagações formuladas e algumas respectivas respostas obtidas:

Questão 1 - O que motivou iniciar a implementação do Gerenciamento de Resíduos na instituição em que você trabalha?

As respostas a essa indagação foram, invariavelmente, relacionadas com a preocupação com o papel que a Universidade exerce enquanto formadora dos futuros profissionais, para que estes atuem de maneira responsável para com o meio ambiente. A adoção desta prática deve contribuir para a formação de profissionais com consciência ecológica diferenciada, e permitir a resolução de problemas existentes em algumas unidades, como enormes volumes de passivo acumulado. Nas palavras do Prof. Dr. Fernando Antonio dos Santos Coelho, coordenador do PGR da UNICAMP:

“...Como a atividade de formação é um dos pontos centrais da função da Universidade, era necessário estabelecer parâmetros condizentes com a nossa função de educadores..."

$\mathrm{Ou}$ ainda, como bem frisou a Profa. Dra. Maria Olímpia de Oliveira Rezende:

“...A obrigação de, como química, isto é, tendo o conhecimento, e como cidadã, isto é, sendo um pouquinho responsável por este pequeno planeta, querer contribuir para uma vida melhor, deixando para as geraçôes futuras um mundo, de preferência, melhor do que o que eu recebi..."

Questão 2 - Quais as principais dificuldades encontradas freqüentemente e por ocasiāo do início da gestão?

Em simetria ao observado, nas respostas à questão anterior, as principais dificuldades relatadas pautam na necessidade de investimento em infraestrutura, apoio institucional e inculturar em toda a comunidade a necessidade de mudar a postura frente à questão dos resíduos. Infelizmente, há o problema da entropia, uma vez que é mais fácil jogar tudo fora, bem longe, do que "perder tempo" com organização. E ainda, o sistema de gerenciamento encontra eco em vários setores, mas, segundo alguns testemunhos, falha entre os docentes. A esse respeito, a Profa. Dra. Regina Rebouças Dalston, idealizadora do PGR da UCB foi bastante incisiva:

“... Encontrei "unzinhos" que agrediam o meio ambiente (jogando residuos na pia, dizendo que eu era "cheia de bobagens", que sempre fazia isso e continuará fazendo, e por ai vai...). Esses foram $e$ sempre serão também descartados pelos próprios alunos e pelo próprio sistema, pois os alunos são os maiores fiscais..."

Questão 3 - Em seu entendimento, para o tratamento de resíduos gerados em uma instituição, seria interessante a existência de um laboratório nesta unidade, responsável pelo tratamento da maioria dos compostos gerados, ou o tratamento deve ser realizado pelo próprio laboratório gerador?

Essa foi a derradeira pergunta formulada aos idealizadores de PGR de diversas instituições, na resposta à qual as opiniōes foram mais dessemelhantes. Há que se concordar que, algumas das vantagens de contar com um laboratório responsável pelo gerenciamento dos resíduos químicos situam-se no fato de se poder padronizar os métodos operacionais de rotulagem, armazenagem, recuperação, tratamento, monitoramento e disposição adequada, o que justifica a opinião da Profa. Maria Olímpia:

“...Deve haver um único laboratório de tratamento, desde que nunca se perca o foco de que o laboratório gerador é o responsável pelos resíduos gerados..."

Por outro lado, há quem entenda que sistema deve vender as facilidades e o gerador deve tratar do que é gerado com o apoio técnico do pessoal atrelado ao gerenciamento. Ocorre que podem existir três níveis de gestão de resíduos: na bancada do laboratório, no laboratório de tratamento e no local de estocagem, e o problema deve ser enfrentado da melhor maneira possível nesses ambientes. Talvez quem melhor exprima essa situação seja o Prof. Dr. José Albertino Bendassolli, coordenador do PGR do CENA/USP: 
“...Em instituiçôes onde o número de unidades geradoras é grande e os residuos são diversificados, pode parecer atrativa a instalação de uma central única de tratamento. Esta opção deve ser analisada com muito cuidado, pois centrais de tratamento quase sempre inibem as iniciativas de abate, ou seja: evitar a geração; minimizar residuos na fonte geradora; reaproveitar, tratar e realizar a disposição final. Além do mais, desestimulam a responsabilidade objetiva...."

\section{REGRAS BÁSICAS A SEREM CONSIDERADAS NA IMPLEMENTACÃO DE PGR EM UNIVERSİDADES}

Uma análise dos procedimentos que estão sendo implementados nas universidades contempladas no presente estudo permitiu elencar algumas regras básicas que devem ser consideradas durante a implementação de um PGR. Sumariamente, essas regras foram condensadas nas sete subseqüentes recomendações:

1) É imprescindível que o responsável pelo resíduo seja o gerador, e deve-se realizar um detalhado inventário que ilustre os resíduos gerados na instituição.

2) Deve-se respeitar a uma hierarquia de gestão que priorize: evitar a geração; minimizá-la; reaproveitar os resíduos inevitavelmente gerados; tratar; e dispor.

3) A correta segregação dos resíduos em classes de compatibilidade é fundamental para tornar viável o gerenciamento.

4) O armazenamento dos resíduos nos laboratórios deve ser realizado em recipiente apropriado, hermeticamente fechado, de capacidade volumétrica reduzida, corretamente identificado e em condições seguras.

5) A etapa de tratamento dos resíduos pode ser realizada dentro ou fora da unidade geradora, através de procedimentos, ao menos em consonância com a legislação vigente.

6) As operaçōes devem ser procedidas dentro de condiçôes ideais de segurança, uma vez que um único procedimento indevido pode resultar em acidente de pequena ou larga escala, sérios danos ao manipulador e demais pessoas nas proximidades do local e, ainda por cima, proporcionar o derramamento de substâncias a serem geridas como resíduos.
7) $\mathrm{O}$ treinamento de pessoal, a divulgação e a realização de qualquer tipo de ação educacional são decisivos para o sucesso de um PGR. Desse modo, todo e qualquer instrumento (Internet, intranet, vídeos, cartilhas, etc.) que auxilie a disseminação desses conceitos e práticas é extremamente válido.

\section{CONSIDERAÇÕES FINAIS}

A realização deste trabalho permitiu concatenar as práticas de gerenciamento que vêm sendo utilizadas em diversas instituiçôes, favorecendo assim a elaboração de um modelo, proposto com o intuito de viabilizar a implantação de programas dessa mesma ordem em outras universidades, além de proporcionar informações que podem servir de auxílio ao aprimoramento dos programas já existentes. Grande parcela dessas recomendaçōes já é observada na maioria das instituiçôes investigadas, o que corrobora suas aplicações efetivas.

É importante reforçar, quanto às sugestôes propostas, que a segregação ou separação e rotulagem (identificação) dos resíduos ativos são as medidas mais relevantes, e que sem elas toda a implementação se inviabiliza, transformando um ativo conhecido e de fácil destinação, em um passivo incógnito, envolvendo um moroso e custoso processo de identificação, além de acarretar em misturas muitas vezes ainda mais perigosas e cujos tratamentos se tornam inviáveis. Esta condição intensifica ainda mais a necessidade de que essas práticas devem ser conduzidas respeitando rígidos padrões de segurança.

Há que ser motivo de reflexão a opinião, pertinente, de alguns professores que participaram da enquête de que algumas pessoas, avessas à correta gestão de resíduos, aparentam não possuir a mesma sorte no quesito consciência, ou até mesmo inteligência, afinal não conseguem perceber que qualquer ação, com intuito benéfico ou não, se propaga e pode ser ampliada. Desta forma, com o descaso ao ambiente, acabam por prejudicar direta ou indiretamente suas próprias vidas e deixam de construir em si pessoas melhores.

Nota-se também que, em poucos programas, são mencionados esforços à disseminação da conscientização ambiental, como o desenvolvimento de cartilhas auto-explicativas, estruturação de programas de visitação para escolas, indústrias e demais interessados no assunto, atividades essas que deveriam ser estimuladas, pois difundem os conceitos de sustentabilidade e responsabilidade objetiva.

Embora a abordagem principal seja referente ao gerenciamento de resíduos químicos, algumas iniciativas adotadas pontualmente poderiam ser reproduzidas na maioria das instituiçôes. Exemplos como a gestão de águas servidas e energia elétrica, conjugada ao programa de gerenciamento de resíduos, denotam maior abrangência, favorecendo não apenas ganhos ambientais, como também financeiros, servindo inclusive de suporte ao re-investimento no programa.

As atividades que somam esforços ao princípio de desenvolvimento sustentável vêm sendo aplicadas nos mais variados setores. Sendo este o quadro atual, as universidades começam a assumir sua responsabilidade com relação ao desenvolvimento de tecnologia e pesquisa, mas principalmente à formação de profissionais conscientes.

Por fim, é meritório frisar que a proposta, ao se implantar um PGR, é a minimização dos impactos gerados pelas atividades da instituição. Uma vez iniciado, este tende a ganhar corpo, pois apresenta aspectos positivos tanto financeira quanto ambientalmente. Dentre estes, destacam-se a redução de gastos com compra de reagentes e consumo em geral, armazenamento, tratamento e disposição de resíduos perigosos, o desenvolvimento de pesquisas e novas tecnologias, a minimização de riscos devido ao incremento à segurança, a valorização e especialização dos profissionais envolvidos, afetando positivamente a qualidade das pesquisas. Este processo caminha sempre ao aprimoramento, podendo ser entendido como um ciclo de melhoramento contínuo, possibilitando a constante minimização dos impactos ambientais, garantindo sempre melhorias na qualidade de vida para a presente e futuras gerações.

\section{REFERÊNCIAS}

AFONSO, J. C. et al. Gestão de resíduos: o testemunho do instituto de quimica da UFRJ. In: $3^{\circ}$ ENCONTRO NACIONAL DE SEGURANÇA EM QUÍMICA, 2004, Niterói. Resumos... 1 CD ROM. 2004.

ALBERGUINI, L. B. A. et al. Laboratório de Resíduos Quimicos do Campus USP-São Carlos - Resultados da experiência pioneira em gestão e gerenciamento de residuos em um campo universitário. Química Nova, São Paulo, v. 26, n. 2, p. 291-295, fev. 2003 
AMARAL, S. T. et al. Relato de uma experiência: recuperação e cadastramento de resíduos dos laboratórios de graduação do Instituto de Química da Universidade Federal do Rio Grande do Sul. Química Nova, São Paulo, v. 24, n. 3, p. 419-423, mar. 2001

AMOUR, M. A. Hazardous laboratory chemicals disposal guide. Boca Raton: Lewis, 546 p. 1996.

ASHBROOK, P. C.; REINHARDT, P. A. Hazardous wastes in academia. Environmen tal Science \& Technology, Easton, v. 19, n. 2, p. $1150-1155$, feb. 1985 .

BARBOSA, D. P. et al. Gerenciamento dos resíduos dos laboratórios do Instituto de Química da Universidade Estadual do Rio de Janeiro como um projeto educacional e ambiental. Engenharia Sanitária e Ambiental, Rio de Janeiro, v. 8, n. 3, p.114-119, jul./sep. 2003

BARTLLET, J. N.; McNABB, W. B. Determination of mercury in organic and inorganic compounds - stannous chloride reduction. Analytical Chemistry, Washington, v. 19, n. 7, p. 484-487, jul. 1947.

BENDASSOLLI, J. A. et al. Reciclagem de cobre proveniente de analisador elementar de carbono e nitrogênio. Química Nova, São Paulo, v. 25, n.2 p. 312-315, feb. 2002.

BENDASSOLLI, J. A. et al. Gerenciamento de resíduos químicos e águas servidas no Laboratório de Isótopos Estáveis do CENA/USP. Química Nova, São Paulo, v. 26, n. 4, p. 612-617, abr. 2003.

BERSCH, G. A.; GONÇALVES, C. V.; MACHADO, M. Gerenciamento de residuos na UNIVATES. In: $3^{\circ}$ ENCONTRO NACIONAL DE SEGURANÇA EM QUÍMICA, 2004, Niterói. Resumos... 1 CD ROM. 2004.

COELHO, F. et al. Implantação do Programa Institucional de Gerenciamento de Residuos da Unicamp - Resultados preliminares. In: 20 ENCONTRO NACIONAL DE SEGURANÇA EM QUÍMICA, Porto Alegre. UFRGS, 1 CD ROM. 2002.

CUNHA, C. J. O programa de gerenciamento de resíduos laboratoriais do depto de química da UFPR. Química Nova, São Paulo, v. 24, n. 3 p. 424-427, mar. 2001.

DALSTON, R. C. R. et al. Resíduos químicos e de saúde das USSF/UCB. In: $3^{\circ}$ ENCONTRO NACIONAL DE SEGURANÇA EM QUÍMICA, 2004, Niterói. Resumos... 1 CD ROM. 2004.

DEMANAN, A. S. et al. Programa de gerenciamento de resíduos dos laboratórios de graduação da Universidade Regional Integrada do Alto Uruguai e das Missões - Campus Erechim. Química Nova, São Paulo, v. 27, n. 4 , p. 674-677, abr. 2004

DI VITTA, P. B. et al. Gerenciamento de Resíduos no Instituto de Química da Universidade de São Paulo. In: 2० ENCONTRO NACIONAL DE SEGURANÇA EM QUÍMICA, Porto Alegre, UFRGS, 1 CD ROM. 2002.

IZZO, R. M. Waste minimization and pollution prevention in university laboratories. Chemical Health \& Safety, p. 29-33, May/June 2000.

JARDIM, W. F. Gerenciamento de residuos quimicos em laboratórios de ensino e pesquisa. Química Nova, São Paulo, v. 21, n. 5, p. 671-673, maio 1998.

KAUFMAN, J. A. Developing a chemical management system. In: KAUFMAN, J. A. (Ed.) Waste disposal in academic institutions. Michigan: Lewis, p. 93-100. 1990.

LOURENÇÃO, B. C. et al. Desenvolvimento de métodos limpos para o tratamento de efluentes contendo ions $\mathrm{Cu}^{2+}$ utilizando quitosana In: ENEQ. $12^{\circ}$ ENCONTRO CENTRO-OESTE DE QUÍMICA, 3., .Resumos... Goiânia, p.52. 2004.

LUNN, G.; SANSONE, E. B. Destruction of hazardous chemicals in the laboratory. 2. ed. New York: John Wiley \& Sons, 501 p. 1994.

MACHADO, P. A. L. Direito ambiental brasileiro. 10. ed. São Paulo: Ed. Malheiros, 1048 p. 2002.

MAGALHÃES, C. E. C. et al. Direct determination of mercury in sediments by atomic absorption spectrometry. Journal of Analytical Atomic Spectrometry, London, v. 12, p. 1231-1234, Oct. 1997.

MORTARI, S. R.; MACHADO, J. C.; BOLSI, J. H. Programa de gerenciamento de residuos químicos do Centro Universitário Franciscano. In 120 ENCONTRO NACIONAL DE QUÍMICA ANALÍTICA, São Luís. UFMA, AB 105. 1 CD-ROM. 2003

REEL, K. Using microscale chemistry: Hydrogen sulfide is not such a rotten idea. Journal of Chemical Education, Easton, v. 70, n. 10, p. 854-856, Oct. 1993.

REIS, B. F. et al. Development of a flow injection system with two analytical paths for ammonium determination in soil extracts by conductometry. Journal of the Brazilian Chemical Society, São Paulo, v. 8, n. 5, p. 523-528, maio 1997.

SARTINI, R. P.; OLIVEIRA, C. C.; ZAGATTO, E. A. G. Determinação turbidimétrica automatizada de cloreto em águas naturais. In: $20^{\circ}$ REUNIÃO
ANUAL DA SOCIEDADE BRASILEIRA DE QUÍMICA, Poços de Caldas. Livro de resumos. São Paulo: SBQ, v. 3, QA-024.1997.

SASSIOTTO, M. L. P.; SALVADOR, N. N. B.; CORNETO, E. C. Gerenciamento de resíduos quimicos na Universidade Federal de São Carlos. In: 3o ENCONTRO NACIONAL DE SEGURANÇA EM QUÍMICA, Niterói, 1 CD-ROM, 2004.

SCHNEIDER, J.; WISKAMP, V. Environmental protection in practical chemistry courses. Journal of Chemical Education, Easton, v. 71, n. 6, p. 587-589, June 1994.

SINGH, M. M. et al. A comparative study of microscale and standard burets. Journal of Chemical Education, Easton, v. 77, n. 5, p. 625-626, Sep./Oct. 2000.

TAVARES, G. A. Implementação de um programa de gerenciamento de residuos químicos é águas servidas nos laboratórios de ensino e pesquisa do CENA/USP. Tese (Doutorado) - Centro de Energia Nuclear na Agricultura, Universidade de São Paulo, Piracicaba, p. 131, 2004.

TAVARES, G. A. et al. Implantação de uma estação de produção de água desionizada para uso nos laboratórios do CENA/USP empregando resinas de troca-iônica. Analytica, São Paulo, n. 10, p. 36-42, abr./maio 2004

ZAGATTO, E. A. G. et al. Manual de análises de plantas e águas empregando sistemas de injeção em fluxo. Piracicaba: CENA/USP, 45 p. 1981.

ZANELLA, G. Gerenciamento de residuos perigosos na FURB em conformidade com a NBR ISO 14001. In: 2० ENCONTRO NACIONAL DE SEGURANÇA EM QUÍMICA, Porto Alegre. UFRGS, 1 CD-ROM. 2002.

\section{Endereço para correspondência:}

Felipe Rufine Nolasco

Av. Centenário, 303 Bairro São

Dimas

Caixa Postal 96

I3400-970 - Piracicaba - SP -

Brasil

Tel: (I9) 3429-4830

E-mail: gtavares@cena.usp.br

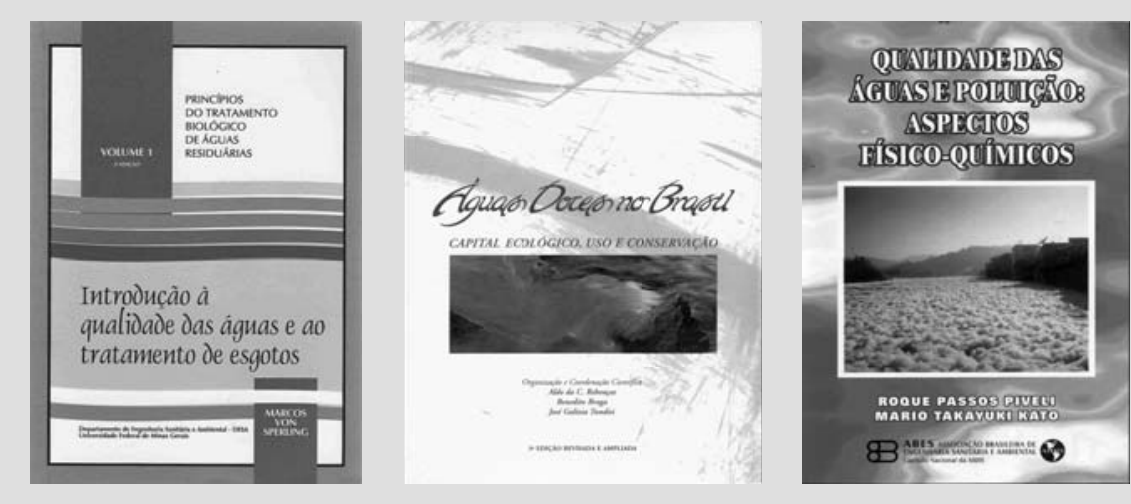

\section{LOJA DE LIVROS ESPECIALIZADA EM SANEAMENTO E MEIO AMBIENTE}

livraria@abes-dn.org.br 